\title{
LA CIUDADANÍA EN TÉRMINOS DE UNA \\ PARADOJA POLÍTICA
}

\section{CITIZENSHIP IN TERMS OF A POLITICAL PARADOX}

\author{
Alejandro Karin Pedraza Ramos* \\ Facultad de Filosofía y Letras, UNAM
}

\begin{abstract}
RESUMEN: En este trabajo se presenta una reflexión teórica para pensar la ciudadanía en términos de una paradoja. La paradoja se presenta porque, si bien la ciudadanía se sustenta sobre el reconocimiento, disfrute y garantía de derechos, el ejercicio ciudadano excede la legalidad en la medida en que denuncia la insuficiencia o injusticia de dicha legalidad y la interpela a cambiar. Para dicho fin, recuperaré la paradoja democrática desarrollada por Chantal Mouffe. A su vez, propondré la paradoja politico-policíalpolicial a partir de Jacques Rancière y la paradoja representación/regulación, desde Étienne Balibar. El objetivo es denunciar como la noción actual de ciudadanía apuesta por la desarticulación del sujeto político que lucha por su derecho a tener derechos.
\end{abstract}

Palabras Clave: democrácia, subjetividad, derechos, participación, vida digna.

АвSTRACT: In this article I present a theoretical reflection in order to think about the citizenship in terms of a paradox. The paradox arises because, although citizenship is based on recognition, enjoyment and guarantee of rights, the citizen's exercise exceeds the legality in that it denounces the insufficiency or injustice of said legality and challenges it to change. For this purpose, I will recover the democratic paradox developed by Chantal Mouffe. At the same time, I will propose the political-police / police paradox from Jacques Rancière and the representation / regulation paradox from Étienne Balibar. The aim is to denounce that the current notion of citizenship aims for the disarticulation of the political subject that fights for its right to have rights.

KeYwords: democracy, subjectivity, rights, participation, dignified life.

* Profesor Asociado "C" de Tiempo Completo, Licenciatura de Desarrollo y Gestión Interculturales, Facultad de Filosofía y Letras, Universidad Nacional Autónoma de México. Rey Nezahualcoyotl 90, CP. 04300, mail: filos_alex@hotmail.com. 


\section{Introducción}

En este trabajo expondré lo que he llamado la noción de ciudadana en términos de una paradoja. Lo cual tiene por objetivo evidenciar como el desarrollo del liberalismo, y actualmente del neoliberalismo, pretende eliminar el sentido de lo político de la política institucionalizada, generando paradojas al intercambiar y oponer los sentidos y prácticas derivadas de la noción de ciudadanía. Con la promesa de que el derecho funcionará como condición de posibilidad para la consecución y desarrollo de los ideales de vida digna de cada persona en lo privado, se promueve como innecesaria la participación política. En la dialéctica política entre emancipación/regulación, limitar el poder del ciudadano para exigir derechos privilegia la idea del derecho como regulación, en demérito de su potencial emancipador y produce a su vez de la inclusión - exclusión de los sujetos políticos y sus demandas.

Para el desarrollo de este trabajo recuperaré algunos de los presupuestos filosóficos de la filósofa belga Chantal Mouffe, y de los filósofos franceses Jacques Rancière y Étienne Balibar. Estos autores, que iniciaron su vida intelectual en el contexto de los procesos de protesta social de 1968 -que inauguró una nueva episteme política en torno a la articulación de los movimientos sociales-, comparten la inquietud teórica por realizar una revisión crítica de los límites políticos de la doctrina filosófico política liberal, así como la poca funcionalidad de sus presupuestos fundamentales en nuestras sociedades actuales; para lo cual realizan también una revisión y reconstrucción crítica del marxismo, alejándose de sus corrientes dogmáticas, y con el objetivo de abonar a la reformulación de un concepto de democracia que permita la garantía de derechos, participación social y emancipación de todas las personas, comenzando por los excluidos de la condición ciudadana ${ }^{1}$.

Recuperaré la paradoja democrática desarrollada por Chantal Mouffe (2012, 2011, 1999), para denunciar que el desarrollo de la democracia contemporánea encubre el sentido político de la política institucionalizada y, en consecuencia, también de la participación ciudadana. Asimismo, para Jacques Rancière (2011,

1 Cabe destacar que Jacques Rancière y Étienne Balibar son discípulos de Althusser y escribirían en el ya célebre libro Para leer el Capital, publicado en 1964, como resultado de un seminario sobre El Capital de Carlos Marx realizado en 1964. Aunque Rancirère, después del 68, se distanciara de Althusser y Balibar tanto personal como ideológicamente, al considerar qua la postura altuseriana era una filosofía del orden (Tarcus, 2015). 
$\left.2010,2007^{\mathrm{a}}, 2007 \mathrm{~b}\right)$, quienes ostentan el poder político institucionalizado odian la democracia entendida como participación, lo que en este trabajo propongo cómo la paradoja político-policíalpolicial; en la cual se establece una lógica policial que sirve para reducir el conflicto político a la fórmula de un litigio jurídico en los términos previamente definidos por la hegemonía. Por último, a partir de Étienne Balibar (2013, 2012a), que sintetiza los aportes de Mouffe y de Rancière, propongo la paradoja representación/regulación; en la cual la ciudadanía establece una dialéctica entre representación y regulación establecida a través del derecho, que al impedir a un sujeto político acceder a la representación política y exigir el reconocimiento y garantía de derechos, se le demeritan las posibilidades de emancipación y realización efectiva de su vida digna.

\section{Aproximación a la noción de ciudadanía}

El problema central de la ciudadanía es la constitución del sujeto libre y autónomo, capaz para participar en la política; sobre una base igualitaria en el disfrute de derechos. Es precisamente la exigencia de derechos el motor de la participación política y la condición de posibilidad de la construcción del sujeto político. La lucha por la ampliación de la igualdad (o democratización), origina la praxis política ciudadana -ciudadanía activa o ciudadanía sustantiva- cuya interpelación es por el "derecho a tener derechos" [Arendt], por el reconocimiento y acceso a derechos negados o vulnerados; frente a la ciudadanía pasiva o formal que supondría el disfrute directo u objetivo del derecho (Tamayo, 2010). Aunque, entre ambas dimensiones hay una relación dialéctica de exclusión y dependencia.

La ciudadanía debe entenderse como un concepto de acción. Si bien la práctica ciudadana, en tanto praxis política no es permanente, el ejercicio de la ciudadanía surge en buena medida a partir de la exigencia de disfrute de un derecho vulnerado o negado. De tal modo que muchas veces los derechos sólo se reconocen a un sujeto político, que al exigirlos, ejerce una presión social y política eficaz. El disfrute de los derechos ciudadanos, aunque tiene una pretensión de universalidad e igualdad, se encuentra permanentemente en un territorio en disputa entre quienes tienen el derecho y quienes luchan por él. La ciudadanía ha sido excedida, porque la ley que le daba forma se ha convertido en una forma vacía en la que los sujetos políticos no ven reconocidas sus exigencias de derechos. 
Derechos que son condiciones de posibilidad para el desarrollo de los ideales de vida digna de las personas.

La ciudadanía genera una relación de opuestos, entre lo que podríamos llamar el momento constituyente y el constituido. La ciudadanía sustantiva, que mediante un conflicto político apuesta por el cambio normativo (constituyente), al ver resuelta su demanda, parece desaparecer para dar paso al tiempo del derecho de la ciudadanía formal (constituido). La ciudadanía formal requiere, para imponerse, que se oculte al sujeto político de la ciudadanía activa, que al exigir derechos origina el conflicto político y la transformación de lo ya constituido. El acto ciudadano es producto de la relación de opuestos y origina una relación dialéctica entre: el ciudadano (sujeto al derecho) y el sujeto político (sujeto de la ruptura normativa). La paradoja se presenta dado que, si bien la ciudadanía se sustenta sobre el reconocimiento, disfrute y garantía de derechos, el ejercicio ciudadano excede la legalidad en la medida en que denuncia la insuficiencia o injusticia de dicha legalidad y la interpela a cambiar.

\section{La paradoja democrática de Chantal Mouffe}

La paradoja democrática surge cuando, detrás de la supuesta inclusión de los ciudadanos en la construcción de la política institucionalizada, se desconoce el conflicto y la diferencia, característicos de lo político. Parecería que el mecanismo del consenso, promovido desde el liberalismo y el neoliberalismo, requiere de la exclusión de lo político para imponerse y funcionar.

Ciudadanía y democracia se encuentran en una relación dialéctica. La pretensión de igualdad que da contenido a la noción democrática ha sido el motor de la ampliación ciudadana, ya sea como participación política o como disfrute de derechos; en tanto que con ello se contribuye al empoderamiento y democratización de la sociedad. Para John Dunn (2014), "lo que resulta especial en el programa democrático es su aserción de que, en última instancia, debe ser el pueblo quien decida lo que se hace" (Dunn, 2014: 218). Aunque no siempre se trató de la aceptación sin más de la estrecha vinculación entre ciudadanía y democracia. La palabra democracia o democratización tardó en aparecer en la medida en que no se aceptó sin más que la totalidad de la sociedad fuera quien legitimara el proyecto político mediante la participación en la política. 
A pesar del vínculo entre democracia y ciudadanía, propiciado por la promoción del sufragio universal, la praxis ciudadana que supondría la ruptura con los privilegios políticos para dar paso al ejercicio democrático del poder, la más de las veces se ve limitada ante la desigualdad de poderes reales para defender los propios intereses.

Siguiendo a Chantal Mouffe (2012), para comprender esta relación paradójica sobre la cual se estructura la democracia moderna es importante enfatizar dos cosas: 1) El ejercicio de los derechos democráticos requiere establecer una distinción de corte schmittiana entre "ellos" y "nosotros", entre "amigos" y "enemigos"; 2) El presupuesto democrático que supone que el poder soberano del pueblo en principio puede decidir lo que mejor le plazca según sus intereses, tiene que ser armonizado simbólicamente con los presupuestos liberales a favor de las libertades individuales y los derechos humanos.

El liberalismo supone que mediante el uso de la razón se lograrían las condiciones suficientes para un consenso basado en acuerdos racionales que no conociera la exclusión. Lo que de fondo implicaría la supresión de los antagonismos y diferencias, constitutivos de las relaciones de poder, que dan sentido al debate democrático. Es decir, opera un desconocimiento implícito de la oposición y el conflicto, que son los motores de la ciudadanía sustantiva:

Una vez que se da por supuesto que la tensión entre la igualdad y la libertad no pude reconciliarse y que sólo pueden existir formas hegemónicas contingentes de estabilización del conflicto, se ve claramente que, tan pronto como desaparece la propia idea de alternativa a la configuración existente del poder, lo que desaparece con ella es la propia posibilidad de una forma legítima de expresión de las resistencias que se alzan contra las relaciones de poder dominantes (Mouffe, 2012: 23).

Para Mouffe, la política es fundamentalmente oposición de proyectos de lo común, aunque, sin ser llevada al extremo en la que los opuestos den lugar al antagonismo entre "amigos" y "enemigos". La apuesta es a favor de una forma verdaderamente política del liberalismo que, sin dejar de postular la defensa de los derechos y el principio de libertad individual, no escamotee la cuestión del conflicto, el antagonismo de la decisión. En este sentido, el objetivo de la política 
como consenso no es la eliminación del conflicto, sino la progresiva eliminación del radical antagonismo - potencial e intrínseco a lo político- de las relaciones sociales. Transformar el antagonismo en agonismo, lo que significaría transformar al enemigo en adversario (Mouffe, 1999: 13).

Lo político trae a cuenta el antagonismo y la hostilidad inherente a las relaciones sociales, producto de los diferentes proyectos de vida en sociedad (Echeverría, 2012). La necesidad de vivir conjuntamente, con "los Otros", hace necesario superar el antagonismo y el conflicto. La política apunta a establecer un orden, a organizar la coexistencia humana en condiciones que son siempre conflictivas, institucionalizando lo político. Aunque, lo relevante es reconocer que es imposible eliminar el conflicto y la lucha por el poder.

El "Otro" es central para todo proyecto político, materializa la idea del "exterior constitutivo". La condición de existencia de toda identidad es la afirmación de una diferencia. La determinación de Otro, que servirá de exterior (incluso de frontera), permite comprender el antagonismo y sus condiciones de emergencia. El "Otro" no es solamente el exterior de un contenido concreto, sino algo que pone en cuestión la concreción como tal. "El ellos no es el opuesto constitutivo del "nosotros" concreto, sino el símbolo de aquello que hace imposible cualquier 'nosotros'” (Mouffe, 2012: 29). La inclusión de la diferencia es fundamental para la constitución de la unidad y la totalidad, pues a la vez que constituye el límite del "nosotros" ejerce un llamado a la alteridad.

El racionalismo con el cual se ha fundamentado el liberalismo, al privilegiar el consenso en la institucionalización de la política, se opone a la democracia entendida como necesidad de hacer co-existir agonísticamente las diferentes posturas de lo político, en la medida en que desconoce y niega el conflicto generado por los movimientos político-sociales o ciudadanías sustantivas. El proyecto democrático debe tomar en cuenta los diversos proyectos políticos en su lucha por el poder y la representación política, de ahí que la democracia deba pensarse como democratización.

La crítica al concepto unitario del consenso racional aparece con el advenimiento del sujeto de la multiplicidad. "Lo que caracteriza las luchas de estos nuevos movimientos sociales es justamente la multiplicidad de posiciones subjetivas que constituyen un único agente y la posibilidad de que esta multiplicidad se convierta en sede de un antagonismo y que, por tanto, se politice" (Mouffe, 1999: 31). Se trata de romper con ideales universales que dan lugar a la exclusión. 
Romper con la figura del sujeto totalizado (formal) y reconocer que no hay identidad pre-establecida, sino que ésta depende de la manera como se articulan entre sí diferentes posiciones subjetivas, estructuradas a partir de una lucha por lo común; se vuelve necesario que la reflexión pase del individuo aislado al intersubjetivo.

Se trata de reconocer el antagonismo, la multiplicidad de proyectos, las marcas de certeza, para dar paso a una democracia que reconozca en plenitud lo político de la participación. "La democracia radical exige que reconozcamos la diferencia -lo particular, lo múltiple, lo heterogéneo-, o sea, todo aquello que el concepto abstracto de hombre excluía. No se rechaza el universalismo, se lo particulariza; lo que hace falta es un nuevo tipo de articulación entre lo universal y lo particular" (Mouffe, 1999: 33). Ya que solo al asumir la paradoja democrática y reconocer el conflicto político se puede dar paso a una política que cumpla con los presupuestos del liberalismo, donde esté efectivamente garantizado cierto grado de libertad personal que permita perseguir los fines propios. Entendiendo "la libertad como la capacidad de los individuos de perseguir sus propias metas" (Mouffe, 1999: 41) y la capacidad para construir el mundo (Mouffe, 1999: 78). El ejercicio de la libertad supondría a su vez la capacidad de promover otro tipo de proyectos políticos, diferentes al dominante; de tal modo que la democracia adquiriría un potencial subversivo. Se requiere romper con la concepción de la libertad, entendida de manera negativa como ausencia de coerción, para dar paso a la libertad como participación política activa.

La verdadera característica de la democracia moderna es impedir la fijación del orden social y hacer imposible que un discurso, o proyecto único de mundo, establezca una sutura definitiva. Un discurso solo puede tener éxito en la fijación temporal de un significado, que tiene que ser parcial y precario debido a las permanentes fuerzas antagónicas. La política debe ajustarse a las necesidades y exigencias de los sujetos políticos y no los sujetos a las opciones institucionales. Es el ejercicio ciudadano que apuesta por un proyecto de mundo en común el que da sentido y fundamento a la exigencia de derechos. Aunque el respeto y la garantía de derechos no es el objetivo, sino las condiciones mínimas de posibilidad que hacen posible la política. 


\section{La paradoja política/policial desde Jacques Rancière}

En este apartado retomo a Jacques Rancière, cuya crítica a la democracia liberal llega a conclusiones similares a las de Chantal Mouffe (aunque sin hacer referencia a ella) respecto al desconocimiento del conflicto político por parte de la democracia de corte liberal. El odio a la democracia da como resultado la paradoja político-política/policial. Y si bien, a diferencia de Mouffe, el autor no propone tal cual una paradoja, su análisis de la política y la democracia enfatiza las contradicciones teórico-fácticas de dichos conceptos y las acciones políticas que los acompañan.

Mientras que, para Mouffe, la democracia es fundamentalmente el espacio del conflicto político que deben resolverse negociadamente superando la figura del consenso racional reconociendo el papel de las pasiones y múltiples racionalidades, para Rancière significa algo más; la democracia, más que describir una forma de relación social, es el articulado mismo de dicha relación. Mediante el principio democrático se determinan los niveles de participación-partición, es decir, se determina el poder de decisión y el tipo de reconocimiento que tiene cada subjetividad política articulada mediante el disenso. En ese sentido, el énfasis de Rancière queda puesto en las contradicciones de la democracia que genera bordes en los cuales son colocados diversos sujetos sociales a fin de ser excluidos de los beneficios de pertenecer a la sociedad. La igualdad sólo puede ser posible y dejar su marca a través del disenso, que afirma y enfatiza la diferencia para reclamar y hacer valer su igualdad de derechos ante la comunidad (Rancière, 2007b).

Para Rancière, el odio a la democracia promovido por los sectores en el poder es connatural a las relaciones políticas en Occidente, por una confusión pocas veces evidenciada, propiciada por la ruptura con los viejos lazos sociales con los que se identificaban las solidaridades naturales e históricas (Rancière, 2007a: 28) y por el abandono de la política por sus representantes autorizados. La paradoja sobreviene al suponer a todos los miembros del "pueblo" iguales en la política, pero negándoles la participación democrática, al delegarla a los competentes.

Para Rancière, la eliminación del orden estamental orgánico y su sustitución por un imaginario de igualdad pretendió imponer mediante el artificio de la ley solidaridades que solo pueden crearse natural e históricamente. Sin embargo, hay una confusión de origen, que afirma, a la vez que encubre, que históricamente han existido dos títulos para gobernar: la superioridad por nacimiento y el 
poder de la riqueza. Y si bien la democracia moderna se afirma sobre relaciones igualitarias, en la realidad se combinan los dos títulos históricos, encubiertos por el presupuesto democrático de delegación del poder a los representantes. De tal modo que la democracia "no es ni un tipo de organización ni una forma de sociedad. [...] Es simplemente el poder propio de los que no tienen más título para gobernar que para ser gobernados" (Rancière, 2007a: 71).

Y si bien el principio de igualdad jurídica ha sido un logro muy importante para nuestras sociedades, hay que recordar que este tipo de igualdad está sustentada en el imaginario del mercado y "tiene una sola causa, la impaciencia del hombre democrático, que trata todas las relaciones según un solo y mismo modelo: las relaciones fundamentalmente igualitarias anudadas entre el prestador de servicios y su cliente" (Rancière, 2007a: 34). Esa misma lógica del mercado, explica porque no todos pueden acceder al disfrute de los derechos, reducidos a servicios, pues no todos pueden pagar por ellos. La crítica a la democracia realizada por Rancière tiene como punto articulador la denuncia al carácter economista y mercantil de las relaciones sociales, marcadas por la lucha de clases y la imposición de los intereses de la oligarquía a las clases trabajadores, que son marginadas y excluidas de la sociedad y las estructuras de poder que permiten el acceso a derechos y toma de decisiones.

En la democracia representativa "el poder de los mejores se justifica sólo por el poder de los iguales" (Rancière, 2007a: 72). La igualdad sólo es experimentada plenamente por los que ejercen el poder, aunque se requiere afirmar la igualdad formal irreductible para que la desigualdad real pueda funcionar. En esta lógica, las leyes juegan un papel central, en la medida en que se presentan como fundamento del poder, ya que "desde el momento en que tiene que haber leyes que se impongan como leyes, e instituciones que encarnen lo común de la comunidad, el mandato debe suponer una igualdad entre el que manda y el que es mandado" (Rancière, 2007a: 72). La democracia representativa, al afirmar la igualdad formal, justifica al mismo tiempo que aquellos a quienes se les delega el poder por ser considerados más "capaces" y "competentes" puedan ser sujetos legítimos de la desigualdad. Por lo que dicho gobierno no puede ser democrático, pues es en el fondo azaroso. No requiere efectivamente de la capacidad o la virtud, su título aparece en el ejercicio mismo de la dominación de la minoría sobre la mayoría.

El objetivo de la democracia representativa es la privatización de la esfera pública a favor de los intereses del grupo en el poder, mediante "un reparto de lo público y lo privado que le asegure a la oligarquía una dominación doble: en 
el Estado y en la sociedad" (Rancière, 2007a: 81). Si bien la implantación de la democracia dio lugar a los siguientes hechos históricos: 1) El reconocimiento de la calidad de iguales y de sujetos políticos a aquellos seres que se consideraban inferiores; 2) Reconocer el carácter público de espacios y relaciones que permanecían restringidos a la discreción del poder de la riqueza; la delegación del poder a los representantes limita la igualdad al ejercicio ciudadano en su relación jurídico política constituida, que ha provocado que "allí donde el pueblo es soberano, no lo es sino en la acción de sus representantes y gobernantes" (Rancière, 2007a: 83). Lo que repercute en el encubrimiento y desconocimiento del conflicto originado al empoderar al pueblo y permitirle enarbolar demandas.

Según esa lógica, la crisis democrática y el "aumento irrefutable de demandas que presionan a los gobiernos, debilitan la autoridad y vuelven a individuos y grupos reaccionarios a la disciplina y a los sacrificios requeridos por el interés común" (Rancière, 2007a: 17), es decir, "lo que provoca la crisis del gobierno democrático no es otra cosa que la intensidad de la vida democrática" (Rancière, 2007a: 18). De tal forma que el buen gobierno democrático sería aquel capaz de controlar el exceso de participación colectiva, considerada un mal, puesto que da lugar al conflicto entre opuestos. Además, al hacer caso a las mayorías se puede dar cabida a un gobierno arbitrario o anárquico.

La relación representación/participación genera a su vez una paradoja enmarcada en la relación conflictiva entre lo político/policial. La subordinación del sujeto político a la figura del ciudadano obliga a que los conflictos políticos queden limitados a los derechos y deberes jurídicos que la ley establece para su resolución, reduciendo el conflicto político a un litigio jurídico. La posibilidad de emancipación supuesta en la exigencia del sujeto político queda subsumida a la regulación jurídica que determinará de que poderes es portador. La reducción del conflicto al litigio, presupone que el consenso sobre las leyes con las que se regula la sociedad no se rompe, lo que de facto reduce la posibilidad de la inclusión de nuevos derechos. Es decir, pretende eliminar la política misma, que significa la inclusión de lo excluido, el reconocimiento de lo negado; el conflicto histórico entre el tener y no tener derechos. Como puntualiza Rancière, " 'tener' y 'no tener' son términos que se desdoblan. Y la política es la operación de ese desdoblamiento" (Rancière, 2007a: 89). La reducción del sujeto político al ciudadano pasivo tiene por finalidad ocultar ese desdoblamiento.

El odio a la democracia es el odio mismo a la política, a saber, el miedo a que los que "no tienen" derechos los "tengan" como producto de su praxis, al 
poner en evidencia que el litigio es insuficiente para resolver su demanda. Pues significaría romper con el consenso y el acuerdo originario, al delatarlos como instrumentos del poder hegemónico.

Lo que he considerado en este trabajo como paradoja representación/regulación, en las categorías de Rancière genera una distorsión operada por el derecho, en la que la política (que antes hemos llamado lo político) muta en lo policial. La política "no es asunto de vínculos entre los individuos y relaciones entre éstos y la comunidad; compete a una cuenta de las partes de la comunidad, la cual es siempre una falsa cuenta, una doble cuenta o una cuenta errónea" (Rancière, 2010: 19). La cuenta se establece al delimitar las partes de la comunidad, a partir de lo que aportan a la comunidad y del derecho que ésta les reconoce a poseer una parte del poder común.

El demos siempre ha pretendido identificarse con el todo, lo múltiple de la cuenta idéntico al todo, la parte como todo, lo múltiple como uno; la identidad como totalidad. Sin embargo, la cuenta, en tanto política, siempre será errónea, ya que siempre hay alguien que no tiene parte en la misma. Los pobres, el tercer estado, el proletariado, por poner algún ejemplo, no tiene parte en la cuenta, son la "parte de los sin parte". "La denuncia de los sin parte es lo que posibilita el surgimiento del disenso, del desacuerdo, al interior de la comunidad política. Pues "la política existe cuando el orden natural de la dominación es interrumpido por la institución de una parte de los que no tienen parte" (Rancière, 2010: 25). El conflicto político al que da lugar la imposible igualdad de lo múltiple cuestiona la cuenta, denuncia un cómputo erróneo e interpela por la inclusión de la parte de los sin parte en la comunidad política, incluso antes de establecer el litigio entre los derechos que refiere como suyos.

El poder hegemónico odia a la democracia, en tanto que esta supone la posibilidad de inclusión de la parte de los que no tienen parte en la política. El poder requiere la negación de la política como espacio del conflicto y de litigio, pues requiere perpetuar que no hay parte de los que no tienen parte (Rancière, 2010: 28). Su apuesta es por el orden, en ello reside la fortaleza policial de la política institucionalizada. Pues "antes que el logos que discute sobre lo útil y lo nocivo, está el logos que ordena y que da derecho a ordenar. Pero este logos primordial está corroído por una contradicción primordial. Hay orden en la sociedad porque unos mandan y otros obedecen" (Rancière, 2010: 31). 
La política irrumpe cuando, apelando a la igualdad, un sujeto político pone en cuestionamiento lo que se presenta como orden natural de dominación. Sin embargo, dicha irrupción ocurre pocas veces en el tiempo cotidiano de la vida, que requiere hacer prevalecer el orden social por medio del derecho, imponiendo policialmente la política institucionalizada. "La policía es, en su esencia, la ley, generalmente implícita, que define la parte o la ausencia de parte de las partes" (Rancière, 2010: 44). En tanto ordenamiento legal, tiene por objetivo regular la vida social, ordenando y regulando lo permitido y lo prohibido. "La policía no es tanto un disciplinamiento de los cuerpos como una regla de su aparecer, una configuración de las ocupaciones y las propiedades de los espacios donde esas ocupaciones se distribuyen" (Rancière, 2010: 45).

La política tiene dos momentos: por un lado, está el momento del orden establecido policialmente, y, por el otro, la ruptura originada por la irrupción de una pretensión de igualdad. Éste último posibilitaría la emancipación del sujeto político, producto del efecto de igualdad. Pero, como contraparte, el orden social para justifica el lugar de cada parte del todo y la desigualdad de los que ejercen el poder y el gobierno requiere anular la política imponiendo el orden policial. "Así, la política no es el nombre de nada. No puede ser otra cosa que la policía, es decir la negación de la igualdad" (Rancière, 2010: 51).

El orden policial se impone a través del derecho, la relación de los sujetos con el todo queda circunscrita a relaciones litigiosas que delimitan las atribuciones de derechos y deberes. La metáfora que justifica la institucionalización de la política, a saber, la necesidad de la paz social que nos sustraiga a la guerra de todos contra todos, es la misma que justifica el establecimiento de un orden policial. Se instaura una confusión original, donde la misma igualdad formal del derecho y el apego irrestricto a los cánones del litigio eliminan la posibilidad real de la igualdad y la libertad.

La realización del sujeto político, cuya finalidad es la emancipación humana, está imposibilitada dentro del orden policial. El ser humano para emanciparse debe trascender la representación contenida en la ciudadanía impuesta policialmente. Al obligar a que la acción política se limite a los términos del litigio de la representación institucionalizada, se oculta la distorsión originaria que desconoce lo erróneo de la cuenta; de este modo: 
Es la verdad oculta bajo esta representación: el hombre de la sociedad civil, el propietario egoísta con el cual hace juego el no propietario cuyos derechos ciudadanos sólo sirven para enmascarar el no derecho radical. El fracaso de la ciudadanía en el cumplimiento de la humanidad verdadera del hombre se convierte en su capacidad de servir, enmascarándolos, los intereses del hombre propietario. La participación política es entonces la mera máscara de la repartición de las partes (Rancière, 2010: 108).

La política, en tanto policía, impone la desigualdad y la justifica mediante el ejercicio del derecho. Lo paradójico del caso es que la sociedad requiere del orden policial para resolver atribuciones de derechos y deberes en conflictos cotidianos. Pero, además, la política aparece en los momentos en que los términos del litigio son insuficientes, cuando la parte de los sin parte irrumpe con exigencias de igualdad, buscando cambiar la forma en que se hace valer el derecho. La ruptura que el conflicto y la diferencia hacen aparecer en el momento de la política requiere dar paso a un orden social institucionalizado o policial, para que sus exigencias de derecho sean efectivas.

El derecho no cambia sin más frente a las exigencias de los excluidos, pues evidenciaría su incapacidad de hacer valer los términos del litigio establecido para nombrar, normar y regular la sociedad. El derecho requiere imponerse para mantener la llamada paz social, los principios institucionalizados de la política. Pues, en virtud de la fuerza que tenga para desconocer el conflicto y la diferencia, está su fortaleza como principio regulador de la sociedad.

Sin embargo, no todo está perdido, pues la parte de los sin parte, mediante sus exigencias de derechos y su pretensión de igualdad dan contenido a movimientos sociales que denuncian los límites del litigio, que la representación jurídico política es insuficiente, que la política institucionalizada policialmente ha sido excedida.

Se trata de evidenciar la apariencia inclusiva de la política imperante y crear nuevas esferas donde aparezca el poder del pueblo, aunque sea de manera fugaz y frágil; ese es el verdadero objetivo de la política. "Aumentar ese poder quiere decir crear casos de litigio y mundos de comunidad del litigio por la demostración, bajo tal o cual especificación, de la diferencia del pueblo consigo mismo" (Rancière, 2010: 114). Para Rancière, esta ampliación debe evidenciar las 
desigualdades reales opresivas en un sentido fundamentalmente económico, aunque en la medida en que el empoderamiento del pueblo tiene por finalidad modificar los términos del litigio y la lógica igualitaria puede ampliarse a la lucha por igualdades complejas. La praxis política denuncia la incapacidad y falta de voluntad para el reconocimiento, de la parte de los que se han quedado sin parte, debido a su diferencia cultural, sexual o económica respecto al grupo hegemónico.

Este uso policial de lo político tiene por objetivo demeritar toda lucha política que apueste por el cambio. Aunque se dice democrático, pretende gobernar sin el pueblo y sin política, al desconocer la participación, la diferencia y el conflicto social. El uso del derecho desde la legalidad hegemónica sirve para mantener el estado de las cosas sin cambio en favor de la oligarquía. Con el argumento de mantener el orden y el consenso social se desconocen las exigencias que apuestan por el reconocimiento de nuevos derechos. Es por ello que la praxis del sujeto político se sitúa en el borde de la legalidad; pues denuncia su insuficiencia y exige su cambio. Se deslegitima y condena jurídicamente toda práctica política que contravenga o cuestione el orden de las cosas, exigiendo re-distribución de bienes y riquezas o el reconocimiento de nuevos derechos. Pues, mediante la lógica policial, atribuir ilegalidad a un proyecto político permite excluirlo de la política. De ser necesario, se puede hacer uso de la fuerza y la sanción para hacer desistir a los sujetos políticos de continuar con sus exigencias, o, en casos extremos, incluso aniquilar y castigar a quienes promuevan un proyecto político que genere diferencia y conflicto.

\section{La paradoja representación/regulación desde Étienne Balibar}

En este apartado me sirvo de Étienne Balibar para desarrollar la paradoja representación/regulación: la participación política no puede ser permanente, requiere dar paso al poder constituido del tiempo cotidiano de la política institucionalizada; pero la regulación tiene por objetivo desanimar la participación constituyente haciendo valer lo constituido. Lo cual funciona en demérito de la participación y la emancipación, entendida como acceso a derechos cambiantes según las necesidades socio-históricas, económicas y políticas que permitan desarrollar una vida digna. 
Étienne Balibar recupera los aportes de Mouffe y Rancière en relación al tema de las contradicciones de la democracia, pero a diferencia de ellos, no se centra en la reflexión de la democracia dentro de las comunidades políticas estatales, sino en la discusión sobre el tema de la ciudadanía, particularmente en su versión cosmopolita. También ha repensado permanentemente las potencialidades del marxismo para entender, explicar y transformar nuestro mundo actual; en ese sentido, el comunismo es resignificado como la democratización radical de la sociedad, lo cual implicaría, a su vez, la ampliación y plena garantía de los derechos de ciudadanía a todas las personas habitantes de Europa, incluyendo a todos los migrantes y los proletarios sometidos a condiciones de marginación. Todo lo anterior, con el objetivo de abonar a la emancipación humana (Tarcus, 2015).

Según Balibar "después del sujeto viene el ciudadano" (Balibar, 2013b: 12). El concepto de ciudadano se impuso discursivamente en un momento histórico atravesado por las revoluciones liberales. Fue necesario romper con la lógica de distribución del poder y sustituir la noción de súbdito antes de conquistar la soberanía del individuo. Es decir, la relación en la que el sujeto al entrar en la comunidad política de los Estados modernos se convierte en ciudadano es más bien una interpretación y una apuesta conceptual que una explicación. La analogía discursiva de dicha sustitución es interesante, pues el súbdito era aquel que se sujetaba a la voluntad y autoridad de un gobernante, mientras que el ciudadano, en tanto sujeto soberano de la modernidad, se sujeta voluntariamente a leyes racionales y razonables, ya sea porque participa en su constitución o porque se reconoce en ellas. De tal manera que podría pensarse que "los súbditos son en este punto, si no "sujetos de derechos", al menos súbditos "en derecho", miembros de una república” (Balibar, 2013b: 56). La regulación tendría como objetivo limitar el poder arbitrario de los gobernantes y la aceptación de la ley por los gobernados.

En este proceso sucede un viraje operado políticamente, cuya finalidad es la sustitución del sujeto político por un sujeto sin política, un ciudadano cuyos poderes se limitan únicamente a los reconocidos mediante un status jurídico. El individualismo liberal rompe con el sujeto de la comunidad, para dar paso al soberano aislado obediente de la ley que protege su derecho a la libertad. Sin embargo, "la libertad no podría en efecto ser pensada más que como aquella del sujeto, del ser sujetado a, es decir, en términos de una contradicción" (Balibar, 2013b: 45). 
El uso discursivo de la noción de ciudadanía sujeta a los individuos a la lógica del poder constituido de la política institucionalizada, que, mediante la normalización y regulación de la vida social, tiene por finalidad desarticular el desdoblamiento de la política como praxis; de ahí que se haga valer policialmente. La noción ciudadana tiene por finalidad ocultar la relación doble que existe entre el sujeto pasivo de la ciudadanía y el sujeto activo cuya participación da lugar a la ruptura, el conflicto y la diferencia.

Para resistir dicha dinámica, es necesario reconocer el carácter insurreccional de la ciudadanía, antinomia sustentada en elementos olvidados de la lógica liberal: el fundamento de limitación del poder por medio del derecho, mediante el primado del derecho sobre el deber; lo que incluye la posibilidad de pensar la praxis ciudadana como figura insurreccional. "Importa hacer el contrapunto de un análisis de la transgresión institucional que no expresa solamente la lógica del deseo, sino las antinomias del saber, los dilemas de la normalización social y las resistencias a la imposición del poder" (Balibar, 2013b: 17). Recuperar la democracia como dinámica de transformación de lo político. Por lo que "la transgresión de la ley, incluso la ley de la transgresión, que no se sabría circunscribir de una vez por todas en los espacios reservados de lo público y de lo privado, es aquí pensada como el destino necesario de la subjetividad que dobla la ciudadanía" (Balibar, 2013b: 25).

El desdoblamiento de la política vino a coincidir con el problema de la construcción del sujeto político y su emancipación, y opuso el discurso del ciudadano al discurso antropológico de la diferencia: el individuo frente a la comunidad. Se evidencia la dialéctica indisoluble entre igualdad y diferencia que la modernidad ha tratado de desconocer acusándola como fuente del conflicto y el desacuerdo. Pues si bien hay una pretensión de afirmar valores universales, como los derechos humanos, estos no pueden dejar de lado las significaciones situadas, inmersas en valores civilizatorios particulares, desde los cuales son enunciados. El reto entonces es ver hasta que punto los discursos universalistas hacen justicia a las necesidades y exigencias situadas de los sujetos concretos (Balibar, 2016).

La subjetividad política irrumpe como resistencia delimitando un espacio de pertenencia, mediante la "identificación" (Balibar, 2005), que delimita el territorio del "nosotros" y el de los "otros", una comunidad que genera fronteras 
internas y externas ${ }^{2}$, pone en entredicho la universalidad de la ciudadanía formal. Estas determinaciones de lo político, apoyadas por su pretensión de igualdad y denunciando la precariedad y la exclusión, buscan generar regímenes de derecho. El sujeto político tiene por objetivo que sus exigencias de derechos sean incluidas en el marco jurídico con el cual se constituye el status jurídico ciudadano. Pues ello implica, a su vez, no solo la ampliación de los derechos y poderes del sujeto jurídico, sino el reconocimiento efectivo de pertenencia a la comunidad política. La praxis política, a través de la lucha por el "derecho a tener derechos", puede tener diferentes niveles de exigencia, ya sea que busque el disfrute de un derecho o del reconocimiento de derechos de otros. Se trata de pensar, por tanto, si los sujetos de la exclusión, pueden ser ciudadanos "por venir".

Lo radical de la exclusión no radica en negar al sujeto el acceso a la representación política ni tampoco en la limitación, precarización o negación de derechos, sino en ser excluido del derecho a luchar por sus derechos. Para Balibar hay en sustancia dos tipos de exclusiones: la externa y la interna. La exclusión externa niega la subjetividad jurídica y los derechos a los que dicho sujeto pudiera apelar, como en el caso de los migrantes ilegales. Por otro lado, la exclusión interna refiere a sujetos quienes, a pesar de tener derechos reconocidos formalmente, no pueden ejercerlos o acceder a su disfrute; en cuyo caso los derechos son virtuales y su no garantía depende de condiciones sociales y políticas. La exclusión interior tiene una relación directa con el status jurídico, el disfrute efectivo de derechos depende de la combinación de prácticas y representaciones en las que queda inscrito. El reconocimiento formal de un derecho es sin duda necesario, "pero su relación con el uso, con la disposición del poder o de la "potencia de

2 En los últimos años Balibar ha centrado sus reflexiones en torno a la noción de ciudadanía, enfatizando el papel de la garantía y negación de derechos a diversos sujetos que se encuentran en nuestras sociedades, tanto aquellos que son considerados externos como los migrantes, como a aquellos que formalmente son parte de la sociedad, pero son mantenidos al margen como los pobres, las mujeres, etc. En este sentido, la noción de frontera es central en tanto que no refiere únicamente a un límite estatal sino sobre todo a un borde simbólico que se enfatiza para negar el acceso a los beneficios de la comunidad. La sociedad reconoce formalmente la pertenencia de todas las personas, pero con criterios diversos los diferentes sectores de la misma establecen fronteras de inclusión y reconocimiento a los "otros", a los que les niega el derecho de pertenecer a dichos grupos y beneficiarse ello. Buena parte de estas ideas son desarrolladas por Balibar en un texto publicado en 1997 con el nombre de La crainte des masses. Politique et philosophie avant et après Marx que como tal no ha sido traducido al español, aunque buena parte de los artículos contenidos en él se encuentran compilados en un texto publicado en 2005 con el título Violencias, identidades y civilidad, en Barcelona por la editorial Gedisa. 
actuar" (empowerment [empoderamiento]) no lo es en menor grado" (Balibar, 2013a: 108).

La exclusión se traduce en negación del poder del excluido e incluso de la capacidad de hacer valer su exigencia de acceso a la distribución del poder. La exclusión no frena el establecimiento de los principios con los cuales se regulará la sociedad y que reconocen, aunque sea formalmente, la soberanía de los ciudadanos, independientemente de que se haga valer o no democráticamente la participación de los ciudadanos. Como apunta Balibar, "en realidad todo depende del modo en el que se instituye positivamente la soberanía del pueblo" (Balibar, 2013a: 33). En dicha positivación, mediante el estatus jurídico se establecen la lógica del litigio que determina las atribuciones de derechos y deberes a cada sujeto. Constitución de un derecho de ciudadanía que tiene por finalidad el establecimiento de normas de redistribución y acceso al poder para beneficio de aquellos que conforman la comunidad política. Aunque "el nomos (la ley) establece una tensión entre reciprocidad y exclusión" (Balibar, 2013a: 31), ya que históricamente no ha podido incluir a la totalidad de los sujetos que se supone constituyen la comunidad política.

Oponerse al cambio y privilegiar la legalidad del poder constituido en aras de la estabilidad y el consenso provoca que el discurso del derecho se vuelva un instrumento a favor del poder hegemónico. De tal manera los sujetos en condición de exclusión interior tienen una alteridad que no puede ser asimilada. Es por ello que la lucha por el reconocimiento de un derecho es a su vez la lucha por el reconocimiento del sujeto político que los exige. Los excluidos, "parte de los sin parte", si bien no disfrutan del derecho, no pueden escapar a cumplir con los deberes que les impone la sociedad, que los sujeta al poder hegemónico mediante la regulación. De ahí que sea "necesario pensar la inclusión y la exclusión como los índices de una inestabilidad esencial de la comunidad de ciudadanos" (Balibar, 2013a: 119).

La inclusión/exclusión a su vez se encuentra normada y regulada, pues establece fronteras de identificación de pertenencia a la comunidad política. Sin embargo, las exclusiones internas no pueden hacerse valer de manera tan simple, ya que se trata de sujetos que en principio pertenecen a la comunidad política. Para Balibar, "no hay procedimiento institucional de exclusión sin una regla, ya sea una regla de derecho o un dispositivo práctico, sociológico" (Balibar, 2013a: 119), que incluye su contraparte, una regla o sistema normativo de inclusión. Aunque no por atender la violencia de la exclusión externa queda librado de 
ella; "la inclusión pude ser igual de violencia, ya sea que se tome la forma de conversión o de asimilación forzosa (en todo caso apremiante, bajo la pena de muerte social)" (Balibar, 2013a: 120), generando dispositivos coloniales, sexistas, de racismo de estado, incluso en sociedades donde no hay de manera oficial ciudadanías disminuidas como los regímenes de apartheid. Se imponen sobre individuos que no son completamente incluidos ni completamente excluidos. Supone tipos de humanos diferentes unos de otros, en razón de las diferencia étnicas, sexual, etaria, de género, de capacidades intelectuales, diferencias entre lo normal y lo patológico, etc., que dan cuenta de las condiciones de imposibilidad reales de la ciudadanía.

Para Balibar, la formula arendtiana del "derecho a tener derechos" como motor de la praxis ciudadana es "una reflexión no sobre la institución de la ciudadanía, sino sobre el acceso a la ciudadanía o, mejor aún, sobre la ciudadanía como acceso y conjunto de procedimientos de acceso" (Balibar, 2013a: 123). Aunque se haga valer el poder constituido como norma biopolítica de regulación social, subyace la permanente necesidad del pueblo de participar y hacerse representar; pues en el fondo solo el pueblo puede decidir obedecer o no obedecer, dejarse regular por el poder constituido o mediante su praxis transformar la institución política.

El conflicto es inevitable en la búsqueda de derechos que materialicen la igual libertad, pues los dominantes no cederán de manera voluntaria sus privilegios a favor de otros. La desigualdad en el disfrute de derechos es una forma de exclusión. La "ampliación de la ciudadanía", en tanto empoderamiento y exigencia de nuevos derechos, "permite comprender por qué las reivindicaciones de poderes ampliados para el pueblo o la emancipación en relación a la dominación que se traduce en nuevos derechos reviste de modo inevitable un carácter insurreccional" (Balibar, 2013a, 54). Pues siempre ha sido producto de una lucha de los excluidos. La llamada ciudadanía social fue producto de la participación activa de sujetos auto-identificados como trabajadores, proletarios, pobres, ciudadanos de segunda clase.

En la medida en que un sujeto histórico logre el reconocimiento de sus intereses y necesidades, (de)mostrando que son intereses generales de la sociedad, universalizables por la conciencia de los sujetos de su condición de exclusión, es que se puede modificar la institucionalidad del poder. El proceso de lucha de los movimientos sociales, mediante su praxis, es el motor del cambio institucional de las normas de la regulación social. La participación 
introduce en la idea misma de democracia un elemento de ciudadanía "anárquica" que sería, sin embargo, la condición de posibilidad de su institución. Tal elemento es evidentemente lo que el constitucionalismo liberal intenta siempre excluir o ignorar: la manifestación periódica o permanente, abierta o latente, de una conflictividad que no se reduce a las reglas de representación o de la comunicación, que pertenece en exceso en relación a todo consenso, o empuja el agonismo más allá de los límites de un pluralismo coherente (Balibar, 2013a: 157).

Debe existir siempre la posibilidad de la insurrección, que mediante el ejercicio del "derecho a tener derechos" rompa con el poder constituido para ajustarse e incluir las exigencias de los sujetos de la exclusión. La lucha por el reconocimiento trae consigo la exigencia de mayor igualdad. De ahí que la democratización de la sociedad signifique empoderamiento de los sujetos políticos, redistribución y ampliación de derechos que le permitan emanciparse, accediendo a una vida digna.

Es por ello que "no se trata de invertir la idea de constitución a favor de la idea de insurrección, sino de hacer vivir la potencia insurreccional de la emancipación en el seno de la constitución política" (Balibar, 2013a: 34). En esta lógica adquieren valor fundamental las declaraciones de derechos humanos, que son la expresión simbólica del conjunto de poderes conquistados por el pueblo a lo largo de su historia y cuya finalidad es la de ser incluidos como derechos de ciudadanía efectivos, reconocidos por el poder constituido de todo Estado que se haga llamar democrático.

\section{Conclusiones: crítica a la ciudadanía}

Como he mostrado en las líneas precedentes, la ciudadanía se presenta como una paradoja política en la medida en que se articula en torno a binomios que generan relaciones antagónicas entre sí. Y si bien no es necesario que dichos antagonismos den lugar a dicotomías radicales, su polarización ha servido para vaciar a la noción de ciudadanía de su sentido político capaz de crear derechos y privilegiar alguna de las valencias en juego: la regulación sobre la representación, lo policial sobre lo político y el consenso sobre el conflicto democrático. Lo 
decisivo es que, en todo caso, ambas valencias son constituyentes de la noción de ciudadanía, a la vez que la hacen oscilar entre su sentido activo y pasivo. El tiempo de la ciudadanía activa creadora de derechos, en algún punto debe dar paso al tiempo del disfrute de derechos, más próximo a la ciudadanía pasiva, pues el objetivo es poder disfrutar de aquellos derechos por los que se lucha. Sin embargo, la cosa no es tan sencilla, pues el contexto socio-político y económico genera dinámicas de las cuales la ciudadanía no puede escapar.

La ciudadanía y la democracia contemporánea se articulan en torno a derechos de propiedad, que ha confundido el concepto de libertad con la libertad para el consumo. "Los ideales liberales conviven con formas de producción que son su negación; las relaciones sociales y las ideas liberales se mezclan y producen un orden que no sólo es jurídico, sino patrimonial” (Durand, 2010: 49). El acceso a bienes y servicios, a bienes de consumo, e incluso salud y educación comienzan a confundirse con poder adquisitivo. Que lejos de conducir a derechos efectivos devienen en "derechos virtuales".

Estos elementos dan cuenta de que la pretendida universalidad de la ciudadanía, así como un cúmulo de derechos para todo humano, están lejos de alcanzarse. Las formas de exclusión se multiplican y cambian constantemente, cada vez son más los excluidos, los marginados, los grupos e individuos que deben sacrificar sus derechos, su autonomía y la confianza en sí mismos por razones que escapan a su control. Obligados a ceder a condiciones de marginación para sobre-vivir indignamente. La ciudadanía ha sido excedida por las condiciones que amenazan la vida de los pretendidos ciudadanos. Los derechos con los que dice proteger y garantizar la vida de los sujetos que constituyen la sociedad son insuficientes, pero incluso los que existen son ineficaces. La exclusión redunda en una restricción efectiva de derechos. La figura y la efectividad del Estado como organismo encargado de mantener un estado de derecho efectivo, y la búsqueda de la ampliación de derechos y por tanto de ciudadanía, parecen fracasar y estar al servicio de intereses como el capital financiero.

La ley con la cual se constituye el Estado de derecho ya no representa, ni puede ser completada con ninguna exigencia material. La ley ya está al servicio de la justicia entre los hombres a los cuales rige, se aplica diferenciadamente bajo una normativa clientelista aún en sus formas limitadas. Es precaria para los individuos excluidos, como si hubiera diferentes niveles de ciudadanía para diferentes individuos, haciendo depender la cantidad y el respeto de derechos del lugar ocupado en la sociedad. 
La ley -siguiendo la sentencia de Alain Badiou (1999) - se ha convertido en una figura de muerte. No atiende a las necesidades de permanencia y desarrollo de la vida de los excluidos, sirve casi exclusivamente a los intereses de los sectores dominantes de la sociedad, haciendo cada vez más amplia la brecha entre los ricos y los pobres, entre los dominantes y los dominados.

El derecho es un intervalo discursivo entre la idealidad y lo real del poder. No se puede prescindir de él, pues es una categoría importante del Estado. Es la legislación interna al Estado la que permite que este mantenga su funcionalidad. Sin embargo, la cristalización y el apego irrestricto a la legislación positiva apelando a la legalidad aniquila la política, cuya esencia debería ser la emancipación de lo colectivo. Lo que hace necesaria una constante adecuación de la norma. El mimetismo jurídico y la normalización en torno a formas sin contenido no sólo corre el riesgo de aniquilar la política, también corre el peligro de desconocer al sujeto al que pretende otorgar derechos, incumpliendo sus necesidades y exigencias y orillándolo a un estado de indefensión que pone en riesgo su capacidad política y amenaza su vida.

La regulación sobre la vida parece ser insuficiente e incluso tramposa, la violencia que se ejerce sobe ella ha tomado múltiples formas, ya no se necesita asesinar directamente al individuo y/o a su comunidad. Ahora se le reconocen derechos y garantías mínimos que por sí mismo no son condiciones de posibilidad de la vida digna. La política en torno a la vida debe reconocer la multiplicidad de existencias o formas de la vida. La vida humana es trans-ontológica y no se cierra a esencialismos, pues un mismo sujeto se ve atravesado por diferentes formas de vida, por diferentes ideales de vida digna, diferentes culturas, tradiciones e incluso diferentes identidades.

La regulación sobre la vida, el derecho, la ley, deben abrir posibilidades de realización a diferentes formas de vida. La ciudadanía, y los derechos asociados a ella, deben ser múltiples y variantes, en función de las diferentes formas de vida; pero, sobre todo, debe ser la respuesta a la exigencia de los excluidos, que al constituirse como sujetos políticos de la ciudadanía activa, articulan sus demandas en torno a derechos que exigen la transformación misma de la ley, apostando por una regulación que les permita emanciparse.

El discurso de la violencia multiplica sus formas, disuelve las afirmaciones y los lugares comunes, excluyendo a identidades colectivas; retirando, restringiendo y regulando, e incluso negando sus derechos ciudadanos. En casos radicales se 
niega incluso la desigualdad como problema público, y en su lugar se afirma, de manera perversa, una pedagogía del hambre para que los marginados "aprendan a trabajar y valorar la vida digna”. Las formas de la exclusión y la marginación se han multiplicado, poniendo a la vida bajo amenaza. Todos los niveles del habitar están bajo amenaza, tanto la institución del Estado como el sin ley de la frontera.

Un análisis crítico de la ciudadanía nos ha permitido identificar las paradojas que constituyen la misma noción ciudadana, así como la lógica de acceso y distribución de poderes.

Si bien lo importante es el establecimiento de una política institucionalizada para regular la vida cotidiana, que incluya derechos, debe establecerse una relación dialectica en la que la regulación y la emancipación no sean contradictorias entre sí. Lo cual significa poder acceder al disfrute de derechos que permitan realizar la vida digna en comunidad. Lo importante es entonces recuperar al sujeto político que sufre exclusión, en tanto doble del ciudadano, que a partir de su poder insurreccionalista puede promover cambios a fin de que el poder constituido le permita emanciparse reconociendo su "derecho a tener derechos".

El ciudadano debe entenderse como el sujeto político capaz de participar en la producción y reproducción de la realidad social en la cual vive. En la medida en que puede defender y llevar a cabo su proyecto político. La ciudadanía depende entonces del ejercicio de derechos y obligaciones que permitan la organización y reproducción de la sociedad. Por lo que la praxis ciudadana es en sustancia ejercicio de un poder. Las relaciones de poder y empoderamiento son su motor natural. Lo cual exige que las luchas por "el derecho a tener derechos" no sean reducidos a problemas de interpretación jurídica, a la forma de resolución de un litigio, sino que posibilite cambiar la lógica del derecho, originando nuevas relaciones jurídicas sustentadas en nuevos derechos.

Para ello, la ciudadanía requiere de la participación política de los sujetos que denuncia la exclusión y exigen el cambio en el disfrute y reconocimiento de derechos; es la lucha por la democratización, por el empoderamiento y acceso al poder. Participar es tomar parte de algo, de la capacidad de tomar a cargo autónomamente su propia vida participando de las regulaciones con las cuales se reconocerá un derecho que permita lograr su proyecto político y la vida digna. 


\section{Agradecimientos / Acknowledgements}

El presente trabajo se realizó gracias a mi participación en:

UNAM. Programa de Becas Posdoctorales de la UNAM. Becario del Instituto de Investigaciones Sociales, asesorado por el doctor Fernando Vizcaíno Guerra.

\section{Bibliografía}

Agamben, Giorgio (1998). Homo Sacer: el poder soberano y la nuda vida. España: PreTextos.

- (2007). Estado de excepción. Buenos Aires: Adriana Hidalgo Editora.

Arendt, Hannah (2006). Los origenes del totalitarismo. México: Taurus.

Benhabib, Seyla (2004). Los derechos de los otros. Extranjeros, residentes y ciudadanos. Barcelona: Editorial Gedisa.

BAdiou, Alain (1999). San Pablo. La fundación del universalismo. Barcelona: Anthropos Editorial.

Balibar, Étienne (1997). La crainte des masses. Politique et philosophie avant et après Marx. Paris: Galilée.

- (2005). Violencias, Identidades y Civilidad. Para una cultura politica global. Barcelona: Editorial Gedisa.

- (2012). "Los dilemas históricos de la democracia y su relevancia contemporánea para la ciudadanía”. Revista Enrahonar. Quaderns de Filosofia, numero 48, pp. 9-29. [http:/www.raco.cat/index.php/enrahonar/article/viewFile/253003/339748 ]. consultado el 3 de noviembre de 2017.

— (2013a). Ciudadanía. Buenos Aires: Adriana Hidalgo Editora.

- (2013b). El ciudadano sujeto, Volumen 1. Argentina: Ediciones Prometeo.

- (2016). Des Universels. Paris: Galilée.

De Sousa Santos, Boaventura (2009). Una epistemología del "Sur". México: Siglo XXI/ CLACSO.

- (2010). Refundación del estado en América Latina. Perspectivas desde una epistemología del Sur. México: Siglo XXI/Siglo del Hombre Editores/Universidad de los Andes.

Dunn, John (2014). Libertad para el pueblo. Historia de la democracia. México: FCE.

Durand Ponte, Víctor (2010). Desigualdad Social y Ciudadanía Precaria ¿Estado de excepción permanente? México: Siglo XXI Editores.

Dussel, Enrique (1998). Ética de la liberación en la edad de la globalización y la exclusión. Madrid: Editorial Trotta. 
- (2001). Hacia una filosofía política crítica. Bilbao: Desclée de Brouwer.

Echeverría, Bolívar (2012). Valor de uso y utopía. México: Siglo XXI Editores.

Heater, Derek (2007). Ciudadanía. Una breve historia. Madrid: Alianza Editorial.

Marshall, T.H. (2005). Ciudadanía y clase social. Buenos Aires: Editorial Losada.

Morales, Cesareo (2010). ¿Hacia dónde vamos? Silencios de la vida amenazada. México: Siglo XXI Editores.

Mouffe, Chantal (1999). El retorno de lo político. Comunidad, ciudadanía, pluralismo, democracia radical. España: Paidós.

- (2011). En torno a lo Politico. México: FCE.

- (2012). La paradoja democrática. El peligro del consenso en la política contemporánea. Barcelona: Editorial Gedisa.

RANCière, Jacques (2007a). El odio a la democracia. Buenos Aires: Amorrortu editores.

- (2007b). En los bordes de lo político. Buenos Aires: Ediciones la Cebra.

- (2010). El desacuerdo. Buenos Aires: Nueva Era.

- (2011). El tiempo de la igualdad: Diálogos sobre política y estética. España: Herder.

Rosanvallon, Pierre (1999). La consagración del Ciudadano. Historia del sufragio universal en Francia. México: Instituto Mora.

TamaYo, Sergio (2010). Crítica de la ciudadanía. México: Siglo XXI Editores.

Tarcus, Horacio (2015). "Leer a Balibar. Viejos y nuevos debates sobre la emancipación”, Revista Nueva Sociedad No 257, julio-agosto de 2015, ISSN: 0251-3552, disponible en: http://132.248.9.34/hevila/Nuevasociedad/2015/no258/13.pdf

Recibido: 15/10/2018

Aceptado: 27/11/2019

Este trabajo se encuentra bajo una licencia de Creative Commons Reconocimiento-No

Comercial-SinObraDerivada 4.0 
